Check for updates

Cite this: RSC Adv., 2018, 8, 38075

Received 29th September 2018 Accepted 29th October 2018

DOI: $10.1039 / c 8 r a 08090 a$

rsc.li/rsc-advances

\section{Rhodamine B derivatives-modified upconversion nanoparticles as a fluorescent turn-off-on sensor for the highly sensitive detection of $\mathrm{Cu}^{2+}$ and pyrophosphate $\uparrow$}

\author{
Zhipeng Meng, ${ }^{a}$ Suli Wu, (D) *a Linghua Zhong, ${ }^{a}$ Min Zeng, ${ }^{a}$ Xiaoqian Sun, ${ }^{a}$ Lu Lib \\ and Shufen Zhang (D) $^{a}$
}

\begin{abstract}
Rhodamine B derivatives (RBP)-modified UCNPs (UCNPs(amSiO $2-R B P$ ) were developed as a fluorescent turn-off-on sensor based on FRET and IFE to detect $\mathrm{Cu}^{2+}$ and pyrophosphate (PPi) with a wide linear response range $\left(0-10 \mu \mathrm{M}\right.$ for $\mathrm{Cu}^{2+}$ and 5-35 $\mu \mathrm{M}$ for $\mathrm{PPi}$, much wider than that reported previously) and high sensibility (117 nM for $\mathrm{Cu}^{2+}$ and $70 \mathrm{nM}$ for PPi). The MTT experiments and the bioimaging experiments show its promising prospect in tissue imaging.
\end{abstract}

\section{Introduction}

Copper ions and pyrophosphate $\left(\mathrm{P}_{2} \mathrm{O}_{7}{ }^{4-}, \mathrm{PPi}\right)$ are critical to human bodies. Excess and lack of $\mathrm{Cu}^{2+}$ ions both can lead to severe diseases such as Alzheimer's disease, while pyrophosphate (PPi) plays an important role in various life activities. Hence, developing an effective method to detect $\mathrm{Cu}^{2+}$ and PPi in environmental and biological samples is very important as they are important bio-functional anions.

Fluorescent sensing strategy is widely used for bio-detection due to its simple, real-time and in vivo detection. The recognition of PPi is generally performed by utilizing metal ion complexes as binding sites because PPi lacks UV-Vis absorbance and fluorescence. The complexing of metal ions with PPi can generate the strong UV-Vis absorbance and thus result in changes in fluorescence signal. Therefore, fluorescence techniques have been employed in the detection of PPi in the past decades. ${ }^{1-3} \mathrm{Cu}^{2+}$ ions can be used to detect PPi due to the strongly complexing ability of PPi to $\mathrm{Cu}^{2+}{ }^{1}$ Several fluorescence probes have been developed to sequentially detect $\mathrm{Cu}^{2+}$ and $\mathrm{PPi}^{4-7}$ However, most fluorescence probes respond mainly to relatively short wavelengths of light irradiation (e.g. UV). This may cause photodamage to tissues, and the lower penetration

${ }^{a}$ State Key Laboratory of Fine Chemicals, Dalian University of Technology, 2 Linggong Road, Dalian 116024, P. R. China. E-mail: wusuli@dlut.edu.cn

${ }^{b}$ Qingdao University of Science and Technology, 53 Zhengzhou Road, Qingdao 266000, P. R. China

$\dagger$ Electronic supplementary information (ESI) available: ${ }^{1} \mathrm{H}$ NMR spectra of RBH and RBP, TEM images of UCNPs and UCNPs@ $\mathrm{mSiO}_{2}$, powder-XRD, EDX spectrum and elemental mapping of the UCNPs, IR spectra and emission intensity of the UCNPs@mSiO ${ }_{2}$, absorption spectra of the PBP and RBH, and selectivity test for the $\mathrm{RBP}$ to the $\mathrm{Cu}^{2+}$, and the linear plot of detection (absorbance) of $\mathrm{Cu}^{2+}$. See DOI: 10.1039/c8ra08090a depth hampers their wide applications to some extent. Recently, upconversion fluorescence probes have earned people's attention due to their unique abilities, which can minimize autofluorescence from the biosamples and enhance the penetration depth in tissues.

To date, hybrids of upconversion nanoparticles (UCNPs) with chromophores have been fabricated for the detection of important biological species and toxins, such as DNA, ${ }^{8} \mathrm{CN}^{-},{ }^{9}$ $\mathrm{Hg}^{2+}{ }^{10} \mathrm{Zn}^{2+},{ }^{11}$ and $\mathrm{H}_{2} \mathrm{~S} .{ }^{12}$ These hybrid sensors are based on the process of energy-transfer from UCNPs to chromophores to "turn on" or "turn off" the upconversion luminescence. Recently, several rhodamine B derivatives RBH-modified UCNP sensors have been reported to detect $\mathrm{Cu}^{2+}$ ions. ${ }^{13-15}$ However, there are very few reports on the use of UCNPs to detect PPi. Wang et al. reported that branched polyethyleneimine (PEI)capped $\mathrm{NaGdF}_{4}: \mathrm{Yb} / \mathrm{Tm}$ UCNPs can be used as a fluorescence probe for the sequential detection of $\mathrm{Cu}^{2+}$ and pyrophosphate $\left(\mathrm{P}_{2} \mathrm{O}_{7}{ }^{4-}\right.$, PPi). ${ }^{4}$ However, the sensor exhibited a narrow linear response range (0.1-2 $\mu \mathrm{M}$ for $\mathrm{Cu}^{2+}$ and $0.5-8 \mu \mathrm{M}$ for PPi). Therefore, it is of importance to develop upconversion probes with a broad liner range.

Herein, we developed a rhodamine B derivative RBP- (RBP was synthesized according to literature, ${ }^{\mathbf{1 6 , 1 7}}$ as shown in Fig. S1 $\dagger$ ) modified UCNPs as a sensor to detect $\mathrm{Cu}^{2+}$ and PPi. RBP was usually used to serve as a "turn-on" fluorescent sensor for $\mathrm{Al}^{3+}$ with strong fluorescent response, but it was rarely reported as a fluorescent sensor for $\mathrm{Cu}^{2+}$ due to its weak fluorescent response. It was found that RBP had only weak UV-Vis absorbance but showed strong fluorescence response to $\mathrm{Al}^{3+}$. In contrast, the response of RBP to the copper is very different from the $\mathrm{Al}^{3+}$, the strong UV-Vis absorbance will appear when $\mathrm{Cu}^{2+}$ was added to RBP solution due to the paramagnetism of copper ions, but the fluorescence response to $\mathrm{Cu}^{2+}$ is weak, 
which shows that RBP has higher responding speed and intensity of UV-Vis absorbance than the traditional probe $\mathrm{RBH}$ to detect $\mathrm{Cu}^{2+} \cdot$. $^{\text {13-15 }}$

In this study, we aimed to achieve efficient FRET (fluorescence resonance energy transfer) and IFE (internal filter effect) from UCNPs to RBP, which was expected to have strong UV-Vis absorbance response. Hence, RBP was selected as a chromophore to modify UCNPs owing to its strong UV-Vis absorbance response towards $\mathrm{Cu}^{2+}$. In the hybrid RBP-UCNPs sensing system, the added $\mathrm{Cu}^{2+}$ will coordinate with $\mathrm{RBP}$ and lead to a strong quenching of the upconversion luminescence. When PPi was present, it could bind strongly with $\mathrm{Cu}^{2+}$ and thus turn on the fluorescence of the UCNPs (Scheme 1).

\section{Results and discussions}

\section{Preparation of UCNPs and the UCNPs@mSiO ${ }_{2}-\mathrm{RBP}$ composite probe}

$\mathrm{NaYF}_{4}: \mathrm{Yb}^{3+}, \mathrm{Er}^{3+} \mathrm{UCNPs}$ were synthesized by the reported coprecipitation method. ${ }^{18}$ To enhance the emission intensity of the UCNPs, an inert layer of $\mathrm{NaYF}_{4}$ was coated onto their surface by a typical core-shell approach. ${ }^{\mathbf{1 9}, 20}$ The TEM images of the asprepared $\mathrm{NaYF}_{4}: \mathrm{Yb}^{3+}, \mathrm{Er}^{3+}$ and $\mathrm{NaYF}_{4}: \mathrm{Yb}^{3+}, \mathrm{Er}^{3+} @ \mathrm{NaYF}_{4} \mathrm{UCNPs}$ displayed uniform shape and size, and the corresponding XRD patterns shown in Fig. S3c $\dagger$ were well indexed to the standard card of $\beta-\mathrm{NaYF}_{4}$ (JCPDS 16-0334). In addition, the luminescence spectra in Fig. S3d $\dagger$ indicate that core-shell strategy significantly improved the luminous intensity. The core-shell structure exhibits strong green emissions at $525 \mathrm{~nm}$ and $546 \mathrm{~nm}$, originating from the transition of ${ }^{2} \mathrm{H}_{11 / 2} \rightarrow{ }^{4} \mathrm{I}_{15 / 2}$ and ${ }^{4} \mathrm{~S}_{3 / 2} \rightarrow$ ${ }^{4} \mathrm{I}_{15 / 2}$ of $\mathrm{Er}^{3+}$. The EDX spectrum of $\mathrm{NaYF}_{4}: \mathrm{Yb}^{3+}, \mathrm{Er}^{3+}$ illustrated in Fig. $\mathrm{S} 4(\mathrm{a}) \dagger$ implies that the main constituents in the studied samples are $\mathrm{F}, \mathrm{Na}, \mathrm{Y}, \mathrm{Yb}$ and Er. Furthermore, the elemental mapping of F, Na, Y, Yb and Er (Fig. S4(c)- $(\mathrm{g}) \dagger$ ) and the total image formed by overlapping the elemental maps also indicate that various elements are well distributed in the entire range of nanoparticles (Fig. S4(b)†).

Aimed towards loading RBP and detecting PPi in aqueous solution, the UCNPs were coated by mesoporous silica $\left(\mathrm{mSiO}_{2}\right)$. UCNPs@ $\mathrm{mSiO}_{2}$ was characterized by TEM, FT-IR and luminescence spectroscopy. The TEM images in Fig. S5a and $\mathrm{b} \dagger$ clearly demonstrate the formation of the $\mathrm{SiO}_{2}$ layer on the surface of UCNPs. Furthermore, through ion exchange with ammonium nitrate, CTAB molecules were removed and $\mathrm{mSiO}_{2}$ were formed. In the FT-IR spectra in Fig. S5c, $\uparrow$ the stretching vibration peaks disappeared, which further confirmed the removal of CTAB. The emission spectra in Fig. S5d $\uparrow$ disclosed that the removal of CTAB has a minor effect on the emission
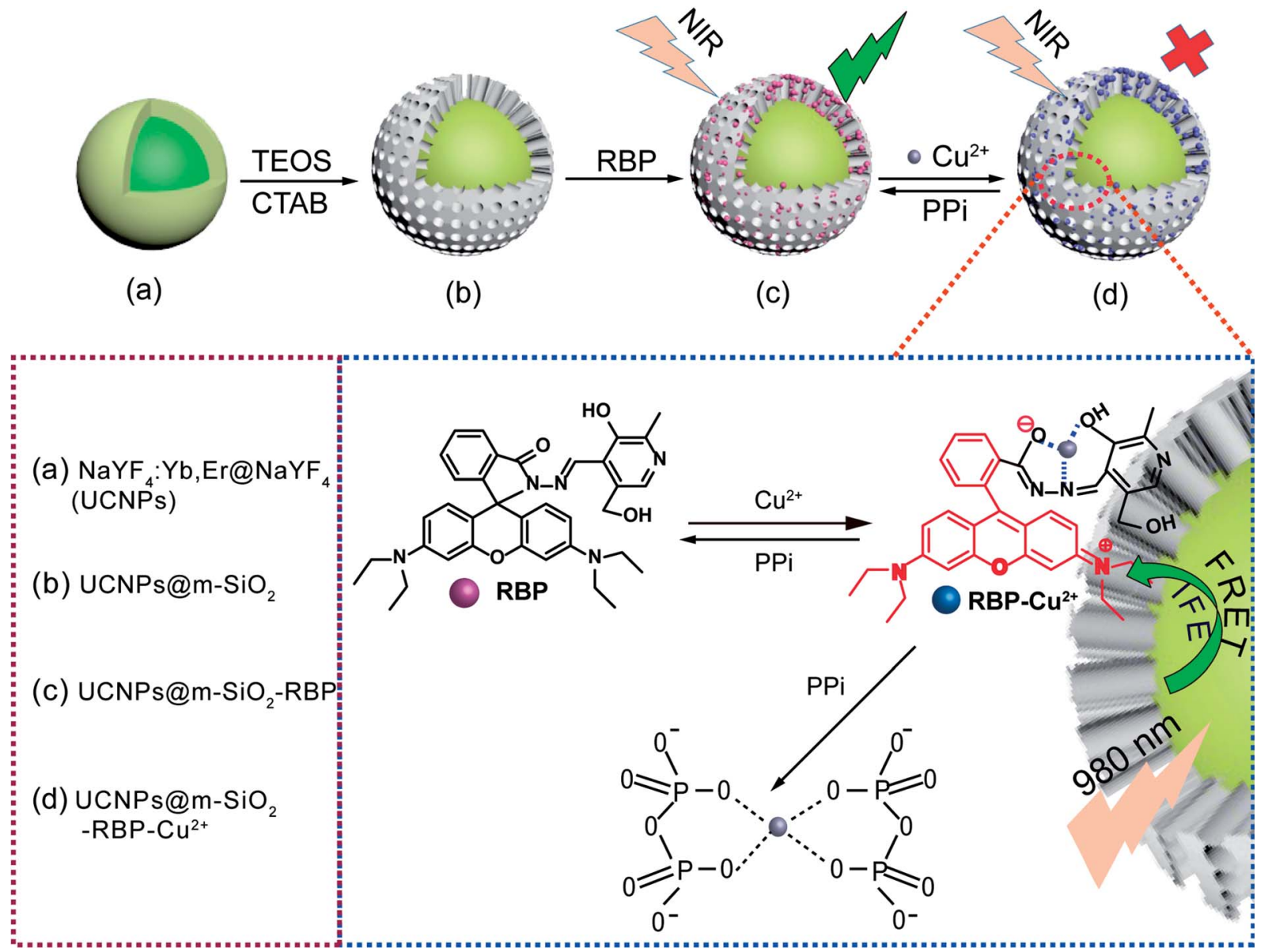

Scheme 1 Schematic of the detection of $\mathrm{Cu}^{2+}$ and PPi by RBP attached with UCNPs. (a) Core-shell UCNPs (b) UCNPsam-SiO 2 (c) UCNPs@m$\mathrm{SiO}_{2}$ absorbed the RBP to form the composite probe (d) composite probe with $\mathrm{Cu}^{2+}$. 
properties of UCNPs. Then, a certain amount of the as-prepared UCNPs@ $\mathrm{mSiO}_{2}$ was added to the $20 \mu \mathrm{M}$ rhodamine B derivative RBP solution and stirred overnight to obtain the fluorescent probe UCNPs@mSiO $\mathrm{O}_{2}-\mathrm{RBP}$.

As shown in Fig. 1a, UCNPs@mSiO ${ }_{2}-\mathrm{RBP}$ showed strong green emissions at $525 \mathrm{~nm}$ and 546 and a weak red emission, similar to that of unmodified UCNPs, because RBP has no evident absorbance in the visible region. However, green emission intensity was significantly quenched after the addition of $\mathrm{Cu}^{2+}$ due to the strong absorbance of RBP- $\mathrm{Cu}^{2+}$ from $520 \mathrm{~nm}$ to $600 \mathrm{~nm}$. The strong affinity between $\mathrm{Cu}^{2+}$ and PPi leads to the formation of the $\mathrm{Cu}^{2+}-\mathrm{PPi}$ complex and results in the detachment of $\mathrm{Cu}^{2+}$ from the UCNPs@ $\mathrm{mSiO}_{2}-\mathrm{RBP}$ probe; thus, the fluorescence is triggered by the addition of PPi. A significant decrease in the $\mathrm{Er}^{3+}{ }^{4} \mathrm{~S}_{3 / 2} \rightarrow{ }^{4} \mathrm{I}_{15 / 2}$ lifetime was observed when $\mathrm{Cu}^{2+}$ was added to UCNPs@mSiO${ }_{2}-\mathrm{RBP}$ from $0 \mu \mathrm{M}$ to $10 \mu \mathrm{M}$ (Fig. 1b, measured with the modified Edinburgh FS5 fluorescence spectrometer under a frequency of $20 \mathrm{~Hz}$ and a pulse width of $300 \mu$ s to modulate the $980 \mathrm{~nm}$ laser), which is solid evidence for FRET. However, the lifetime of $\mathrm{Er}^{3+}$ emission changed slightly when the concentration of $\mathrm{Cu}^{2+}$ was increased from $10 \mu \mathrm{M}$ to $15 \mu \mathrm{M}$, while the PL intensity of the composite probe decreased significantly (Fig. 2b), indicating that IFE also worked in this quenching process. These results suggest that FRET and IFE are the two main processes in the detection process.

\section{Detecting $\mathrm{Cu}^{2+}$ and PPi}

First, the sensing ability of UCNPs@mSiO ${ }_{2}-\mathrm{RBP}$ towards $\mathrm{Cu}^{2+}$ was studied by UV-Vis absorbance spectroscopy with different concentrations of $\mathrm{Cu}^{2+}$. From the absorbance spectra (Fig. 2a), it can be found that the absorbance intensity at the peak (500-600 $\mathrm{nm}$ ) increased with the increase in concentration of the $\mathrm{Cu}^{2+}$ ion. Fig. $\mathrm{S} 6 \dagger$ shows the linear plot of the concentration of $\mathrm{Cu}^{2+}$ versus the absorbance intensity.

To certify the energy transfer of UCNPs emission to RBP, the effect of $\mathrm{Cu}^{2+}$ concentration on the upconversion emission intensity of the UCNPs@mSiO $\mathrm{M}_{2}$-RBP sensing system was explored. Fig. $2 \mathrm{~b}$ shows a gradual decrease of green upconversion emission intensity with the increase in amount of $\mathrm{Cu}^{2+}$ in

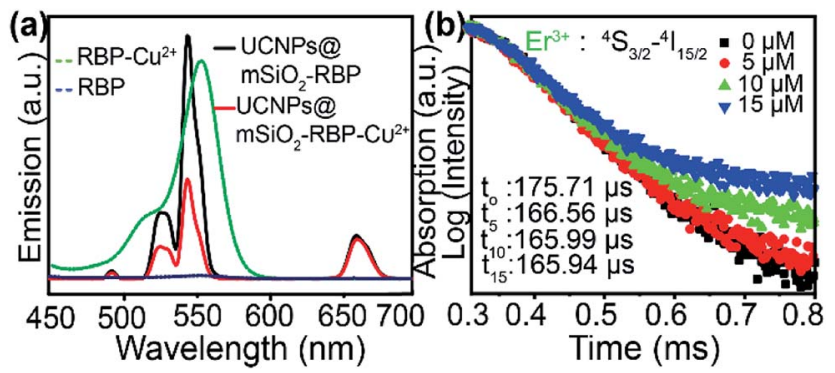

Fig. 1 (a) The absorbance spectrum of RBP- $\mathrm{Cu}^{2+}$ and RBP and the emission spectrum of UCNPsamSiO $\mathrm{m}_{2}-\mathrm{RBP}$ and UCNPs@mSiO${ }_{2}-$ $\mathrm{RBP}-\mathrm{Cu}^{2+}$ in the ethanol-water solution. (b) $\mathrm{Er}^{3+}$ decay curves recorded for UCNPs $\mathrm{amSiO}_{2}-\mathrm{RBP}$ with different concentrations of $\mathrm{Cu}^{2+}$ from 0 to $15 \mu \mathrm{M}$ in the ethanol-water solution.
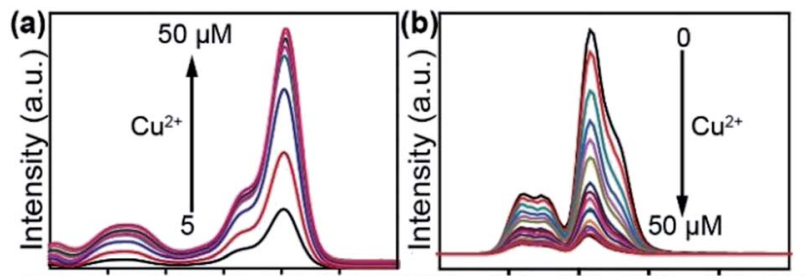

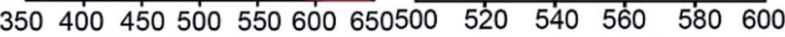
Wavelength $(\mathrm{nm})$

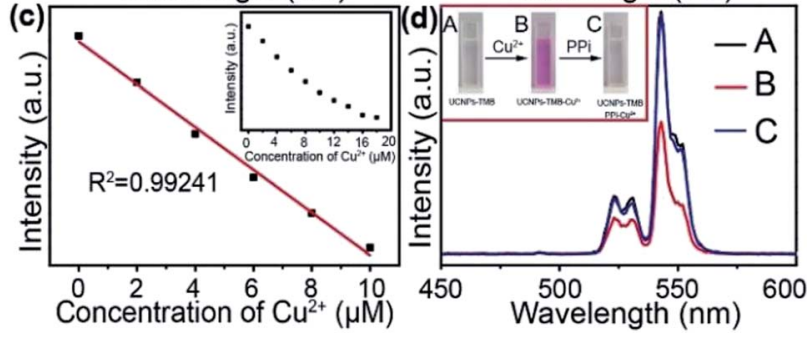

Fig. 2 (a) UV-Vis spectra of UCNPsamSiO ${ }_{2}-\mathrm{RBP}$ dispersion with different concentrations of $\mathrm{Cu}^{2+}(0-50 \mu \mathrm{M})$ in the solution of ethanolwater. (b) Fluorescence spectra of UCNPs@mSiO ${ }_{2}-\mathrm{RBP}$ dispersion upon the addition of different concentrations of $\mathrm{Cu}^{2+}(0-50 \mu \mathrm{M})$ in the solution of ethanol-water. (c) The linear plot of the detection (emission) of $\mathrm{Cu}^{2+}$, the inset is scatter plot for different concentrations of $\mathrm{Cu}^{2+}(0-20 \mu \mathrm{M})$. (d) The digital images of colour changes after the addition of $\mathrm{Cu}^{2+}$ and PPi in sequence and its emission spectra in the ethanol-water solution.

the range of $0-50 \mu \mathrm{M}$. When the $\mathrm{Cu}^{2+}$ concentration reached 50 $\mu \mathrm{M}$, the upconversion emission at $540 \mathrm{~nm}$ quenched by about $92 \%$ of the initial emission intensity of UCNPs@mSiO $\mathrm{U}_{2}-\mathrm{RBP}$. As shown in Fig. 2c, the concentration of $\mathrm{Cu}^{2+}$ exhibited a linear correlation with the emission intensity of UCNPs@ $\mathrm{mSiO}_{2}-\mathrm{RBP}$ with an $R^{2}$ of 0.99241 in the concentration range of $0-10 \mu \mathrm{M}$, which was much wider than that for the recently reported fluorescence methods. ${ }^{4}$ The limit of detection for the concentration of $\mathrm{Cu}^{2+}$ was calculated to be $117 \mathrm{nM}$ based on $3 \sigma / \mathrm{slop}$, where $\sigma$ was the standard deviation of the blank samples and slop was the slope of the calibration curve. Herein, RBP has relatively broader linear range than previously reported $\mathrm{RBH}$, which can be reasoned by the different intensities of UV-Vis of RBP and $\mathrm{RBH}$ toward $\mathrm{Cu}^{2+}$, shown in Fig. $\mathrm{S} 2 . \dagger$ The high sensibility for $\mathrm{Cu}^{2+}$ of RBP can be attributed to its molecular structure. RBP was synthesized by $\mathrm{RBH}$ and pyridoxal hydrochloride (as shown in Fig. S1†), which has larger electron cloud density than $\mathrm{RBH}$ and thus, it can combine with $\mathrm{Cu}^{2+}$ more easily.

To prove the high selectivity of the developed sensor for $\mathrm{Cu}^{2+}$, the effect of other cations, including $\mathrm{K}^{+} \mathrm{Ca}^{2+} \mathrm{Na}^{+} \mathrm{Zn}^{2+} \mathrm{Ba}^{2+}, \mathrm{Al}^{3+}$ and $\mathrm{Mn}^{2+}$, on the UV-Vis absorbance spectrum was investigated. When the concentration of $\mathrm{Cu}^{2+}$ was maintained at $20 \mu \mathrm{M}$ and that of other cations was $100 \mu \mathrm{M}$, no apparent signal change was observed in contrast to $\mathrm{Cu}^{2+}$ except for the signal change due to $\mathrm{Al}^{3+}$, as shown in Fig. $\mathrm{S} 7, \dagger$ which displayed a slight response to UV-Vis irradiation at $520-560 \mathrm{~nm}$.

The fluorescence intensity of the system could be recovered on adding PPi to the system, which can be attributed to the stronger coordination effect between PPi with $\mathrm{Cu}^{2+}$ than RBP since PPi can effectively withdraw the $\mathrm{Cu}^{2+}$ from the complexes of UCNPs@mSiO ${ }_{2}-\mathrm{RBP}-\mathrm{Cu}^{2+}$. In fact, the same mechanism for 
detecting PPi has been described in previously reported studies. ${ }^{6,21,22}$ The photographs of UCNPs@ $\mathrm{mSiO}_{2}-\mathrm{RBP}$ and the emission spectra of UCNPs@mSiO $2-R B P$ after adding $\mathrm{Cu}^{2+}$ and PPi in sequence (Fig. 2d) clearly showed this fluorescence "turnoff-on" process.

At the same time, we also studied the sensing ability of UCNPs@mSiO ${ }_{2}-\mathrm{RBP}-\mathrm{Cu}^{2+}$ toward PPi via UV-Vis absorbance spectroscopy. The absorbance intensity of UCNPs@mSiO ${ }_{2}^{-}$ $\mathrm{RBP}-\mathrm{Cu}^{2+}$ decreased linearly in a certain range $(0-15 \mu \mathrm{M}$, Fig. $3 \mathrm{~b}$ ) with the increase in concentration of PPi (Fig. 3a), which approved that the strong complexing of PPi with $\mathrm{Cu}^{2+}$ plays a crucial role in this process.

To examine the feasibility of using UCNPs@ $\mathrm{mSiO}_{2}-\mathrm{RBP}-$ $\mathrm{Cu}^{2+}$ as the turn-on sensing probes for PPi, different concentrations of PPi were added into the solutions containing UCNPs@ $\mathrm{mSiO}_{2}-\mathrm{RBP}$ (RBP: $20 \mu \mathrm{M}, \mathrm{UCNPS} @ \mathrm{mSiO}_{2}: 10 \mathrm{mg}$ $\left.\mathrm{mL}^{-1}\right)$ and $\mathrm{Cu}^{2+}(20 \mu \mathrm{M})$ under optimal conditions. Fig. 3c shows that the fluorescence intensity of the system could be gradually recovered on increasing the concentration of PPi, and almost $100 \%$ of the initial fluorescence intensity recovered when the concentration of PPi reached $45 \mu \mathrm{M}$. In addition, a linear fitting curve of fluorescence intensity versus concentration of PPi was obtained in the range of 5-35 $\mu \mathrm{M}$, with an $R^{2}$ value of 0.99672 (Fig. 3d). The limit of detection (LOD) was estimated to be $70 \mathrm{nM}$ based on $3 \sigma /$ slop. Compared with the reported results of the detection of $\mathrm{Cu}^{2+}$ and PPi (Table S1 and S2 $\dagger$ ), our results also show the good ability for ion detection.

The specificity of UCNPs@ $\mathrm{mSiO}_{2}-\mathrm{RBP}-\mathrm{Cu}^{2+}$ toward PPi was also evaluated; the fluorescence response of UCNPs@ $\mathrm{mSiO}_{2}-$ $\mathrm{RBP}-\mathrm{Cu}^{2+}$ toward PPi was examined with the existence of $\mathrm{PO}_{4}{ }^{3-}$, $\mathrm{HPO}_{4}{ }^{2-}, \mathrm{H}_{2} \mathrm{PO}_{4}{ }^{-}, \mathrm{Ac}^{-}, \mathrm{SO}_{4}{ }^{2-}, \mathrm{HSO}_{4}{ }^{-}$or $\mathrm{F}^{-}$inions under the

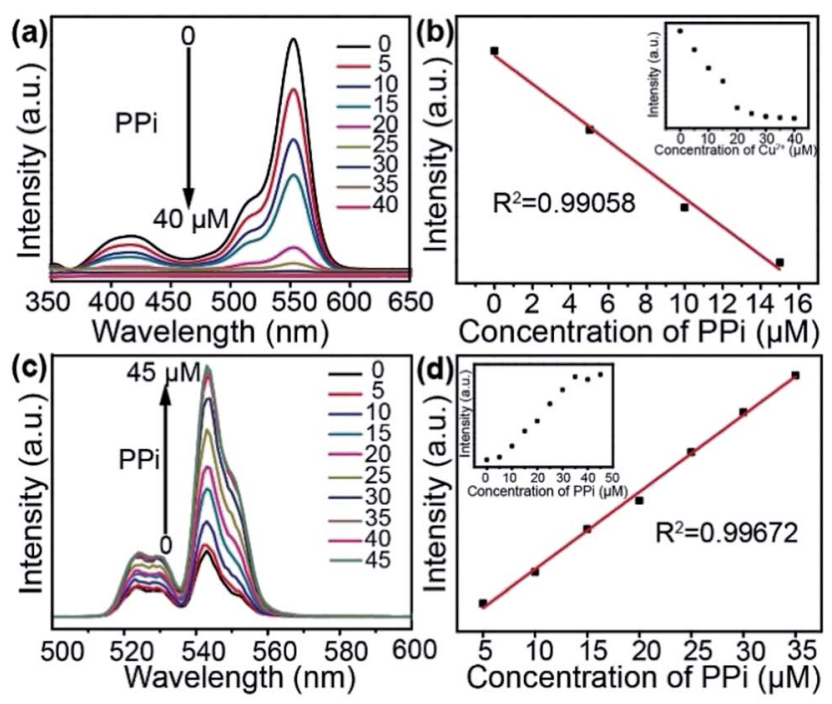

Fig. 3 (a) UV-Vis spectra of UCNPsamSiO $2-R B P$ dispersion with different concentrations of PPi. $(0-40 \mu \mathrm{M})$ in the ethanol-water solution. (b) The linear plot of detection (absorbance) of PPi, the inset is the scatter plot of different concentrations of PPi $(0-40 \mu \mathrm{M})$. (c) The fluorescence spectra of UCNPs $\mathrm{amSiO}_{2}-\mathrm{RBP}-\mathrm{Cu}^{2+}$ with different concentrations of PPi $(0-45 \mu \mathrm{M})$ in the ethanol-water solution. (d) The linear plot of detection (emission) of PPi, the inset is a scatter plot of different concentrations of PPi.

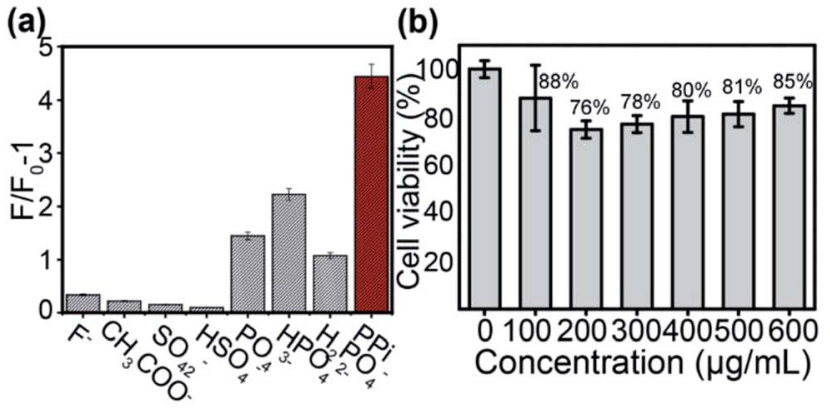

Fig. 4 (a) Selectivity for PPi detection in the ethanol-water solution. (The concentration of PPi and the other anions is $100 \mu \mathrm{m}$, where $F_{0}$ is the fluorescence intensity of UCNPs $a m \mathrm{miO}_{2}-\mathrm{RBP}-\mathrm{Cu}^{2+}$, and $F$ is the fluorescence intensity of the UCNPs $\mathrm{amSiO}_{2}-\mathrm{RBP}-\mathrm{Cu}^{2+}$ with the added anions.) (b) Cell viabilities of HeLa cells incubated with RBPcapped UCNPs at different concentrations $(0,100,200,300,400,500$, $600 \mu \mathrm{g} \mathrm{mL}^{-1}$ ) for $24 \mathrm{~h}$.

same concentration as PPi. Fig. 4a shows the intensity of $\left(F / F_{0}-\right.$ 1) against the concentrations of PPi and other anions. It is evident that only PPi resulted in drastic fluorescence recovery. The anions $\mathrm{PO}_{4}{ }^{3-}, \mathrm{HPO}_{4}{ }^{2-}, \mathrm{H}_{2} \mathrm{PO}_{4}{ }^{-}$also caused fluorescence recovery to some degree, which may be due to the similar chemical structures to form stable metal chelates. The influence of phosphate anions could be considered to be acceptable due to the much weaker recovered fluorescence intensity than that recovered by $\mathrm{PPi}$, while other anions had slight effects on changes in fluorescence intensity. These results indicated that our probe had good specificity for PPi detection.

\section{Cell cytotoxicity and in vivo imaging of the composite probe}

The effect of UCNPs@mSiO ${ }_{2}-\mathrm{RBP}$ on the proliferation of HeLa cells was investigated by a standard MTT assay. As shown in Fig. $4 \mathrm{~b}$, the cell viability is still satisfactory when the concentration of the nanoprobe is raised to $600 \mu \mathrm{g} \mathrm{mL} \mathrm{m}^{-1}$. These results show that the cytotoxicity of the composite probe is weak, and can be applied in bioimaging.

Furthermore, bioimaging experiments were performed. All procedures and operations were performed according to the Guide for the Care and Use of Laboratory Animal Resources and the National Research Council, and were approved by the Institutional Animal Care and Use Committee of the NIH.

Nude mice $(\sim 10 \mathrm{~g})$ were purchased from the Dalian Medical University (Dalian, China) and were used in imaging studies. $100 \mu \mathrm{L}$ of $0.9 \% \mathrm{NaCl}$ saline solution containing the RBP-coated UCNPs $\left(10 \mathrm{mg} \mathrm{mL}^{-1}\right)$ were subcutaneously injected into the back area of nude mice ( $\sim 10 \mathrm{~g})$ anesthetized with chloral hydrate. The mice were then imaged using a modified NightOWL II LB983 small animal in vivo imaging system equipped with a sensitive charge-coupled device (CCD) camera with the excitation of a $980 \mathrm{~nm}$ laser (c.w.). Other mice underwent the same process except with an injection of $100 \mu \mathrm{L}$ of $\mathrm{Cu}^{2+}$ solution $(50 \mu \mathrm{M})$ in the same place after injecting UCNPs@mSiO ${ }_{2}-\mathrm{RBP}$. As shown in Fig. 5, in vivo imaging shows the promising prospect in tissue imaging, and the decrease in the imaging intensity from 1141 to 718 after injecting $\mathrm{Cu}^{2+}$ indicated that UCNPs@ $\mathrm{mSiO}_{2}-\mathrm{RBP}$ has good ability to detect $\mathrm{Cu}^{2+}$ in vivo. 


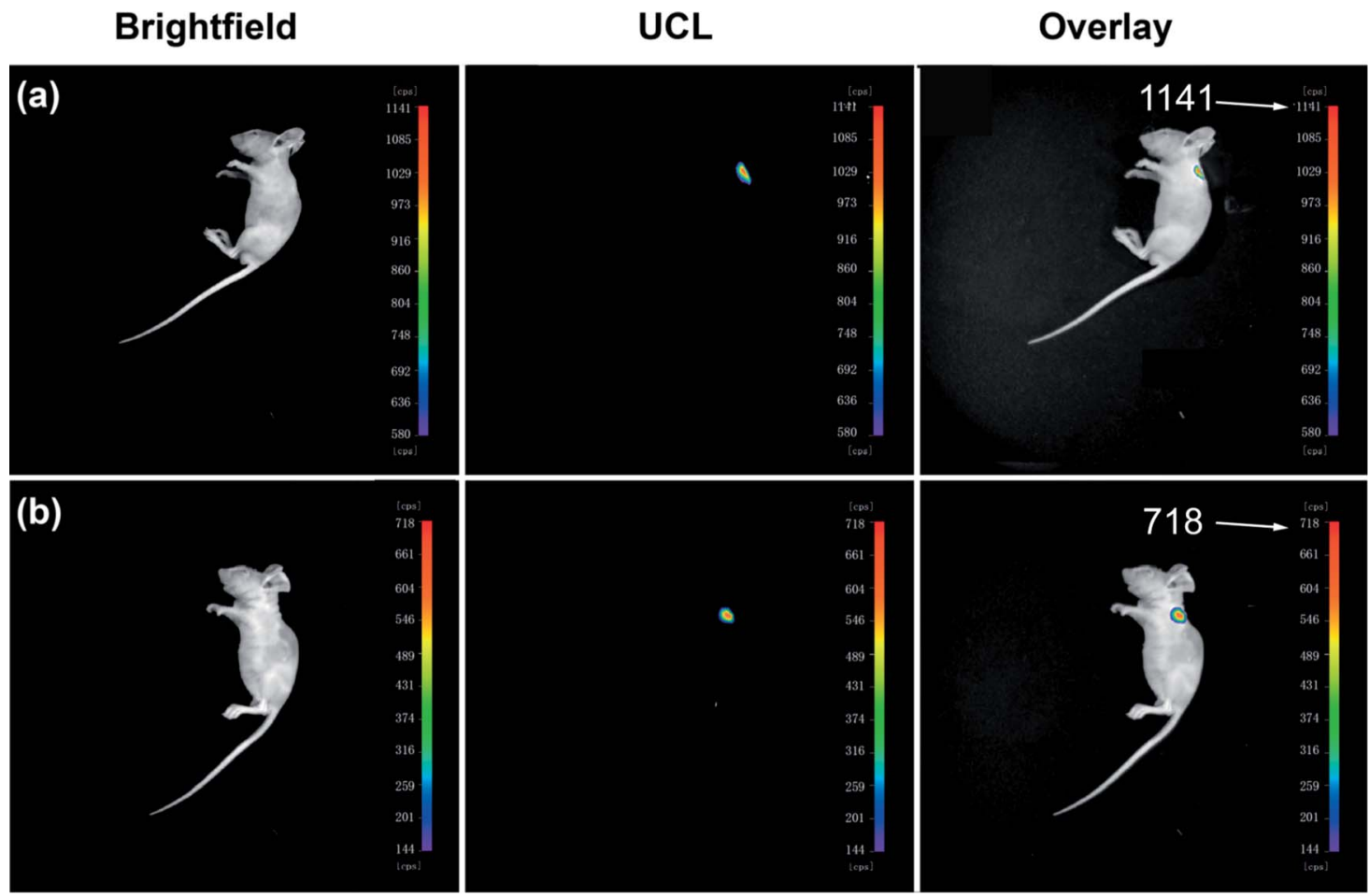

Fig. 5 In vivo upconversion luminescence (UCL) imaging of nude mice with (a) subcutaneous injection of $U C N P s\left(a m S i O_{2}-R B P\left(10 \mathrm{mg} \mathrm{mL}^{-1}\right)(\mathrm{b})\right.$ subcutaneous injection of UCNPs $\left(\mathrm{mSiO}_{2}-\mathrm{RBP}\left(10 \mathrm{mg} \mathrm{mL}^{-1}\right)\right.$ and $\mathrm{Cu}^{2+}(50 \mu \mathrm{M})$, sequentially.

\section{Conclusions}

In summary, in this study, we used RBP-modified UCNPs@mSiO as a probe to detect $\mathrm{Cu}^{2+}$ and PPi. The results show that the fluorescence intensity of $\mathrm{UCNPS}_{\mathrm{mSiO}}-\mathrm{RBP}$ is almost linear with the concentrations of $\mathrm{Cu}^{2+}$ ions in the range of $0-10 \mu \mathrm{M}$. The detection limit is $117 \mathrm{nM}$. We further used the UCNPs@ $\mathrm{mSiO}_{2}-\mathrm{Cu}^{2+}$ complex as a probe to detect PPI because of the strong interactions between PPi and $\mathrm{Cu}^{2+}$. These results show that the fluorescence intensity of UCNPs@mSiO ${ }_{2}-\mathrm{RBP}-\mathrm{Cu}^{2+}$ has a strong linear correlation with the concentration of PPi ion in the range of 5-35 $\mu \mathrm{M}$, and the detection limit is about $70 \mathrm{nM}$. The cytotoxicity of this sensing system is weak, and in vivo imaging shows its promising prospect in tissue imaging and good ability to detect $\mathrm{Cu}^{2+}$ in vivo.

\section{Experimental}

Experimental details and characterization data can be found in the ESI. $\dagger$

\section{Conflicts of interest}

There are no conflicts to declare.

\section{Acknowledgements}

This study was financially supported by the National Natural Science Foundation of China (21878042, 21476040, 21276040, 21536002) and the Fund for Innovative Research Groups of the National Natural Science Fund Committee of Science (21421005).

\section{Notes and references}

1 Z. S. Qian, L. J. Chai, Y. Y. Huang, C. Tang, J. Jia Shen, J. R. Chen and H. Feng, Biosens. Bioelectron., 2015, 68, 675680.

2 S. Kim, M. S. Eom, S. K. Kim, S. H. Seo and M. S. Han, Chem. Commun., 2013, 49, 152-154.

3 X. Feng, Y. An, Z. Yao, C. Li and G. Shi, ACS Appl. Mater. Interfaces, 2012, 4, 614-618.

4 F. Wang, C. Zhang, Q. Xue, H. Li and Y. Xian, Biosens. Bioelectron., 2017, 95, 21-26.

5 L. Wang, Q. Song, Q. Liu, D. He and J. Ouyang, Adv. Funct. Mater., 2015, 25, 7017-7027.

6 S. Lee, K. K. Y. Yuen, K. A. Jolliffe and J. Yoon, Chem. Soc. Rev., 2015, 44, 1749-1762.

7 X. Huang, Z. Guo, W. Zhu, Y. Xie and H. Tian, Chem. Commun., 2008, 5143-5145.

8 M. Kumar, Y. Guo and P. Zhang, Biosens. Bioelectron., 2009, 24, 1522-1526.

9 L. Yao, J. Zhou, J. Liu, W. Feng and F. Li, Adv. Funct. Mater., 2012, 22, 2667-2672.

10 Q. Liu, J. Peng, L. Sun and F. Li, ACS Nano, 2011, 5, 80408048.

11 J. Peng, W. Xu, C. L. Teoh, S. Han, B. Kim, A. Samanta, J. C. Er, L. Wang, L. Yuan, X. Liu and Y. T. Chang, J. Am. Chem. Soc., 2015, 137, 2336-2342.

12 J. Peng, C. L. Teoh, X. Zeng, A. Samanta, L. Wang, W. Xu, D. Su, L. Yuan, X. Liu and Y.-T. Chang, Adv. Funct. Mater., 2016, 26, 191-199. 
13 B. Gu, M. Ye, L. Nie, Y. Fang, Z. Wang, X. Zhang, H. Zhang, Y. Zhou and Q. Zhang, ACS Appl. Mater. Interfaces, 2018, 10, 1028-1032.

14 Y. Xu, H. Li, X. Meng, J. Liu, L. Sun, X. Fan and L. Shi, New J. Chem., 2016, 40, 3543-3551.

15 C. Li, J. Liu, S. Alonso, F. Li and Y. Zhang, Nanoscale, 2012, 4, 6065-6071.

16 Q. Huang, Q. Zhang, E. Wang, Y. Zhou, H. Qiao, L. Pang and F. Yu, Spectrochim. Acta, Part A, 2016, 152, 70-76.

17 Y. Xiang, L. Mei, N. Li and A. Tong, Anal. Chim. Acta, 2007, 581, 132-136.
18 F. Wang, R. Deng and X. Liu, Nat. Protoc., 2014, 9, 16341644.

19 P. Ghosh, J. Oliva, E. D. l. Rosa, K. K. Haldar, D. Solis and A. Patra, J. Phys. Chem. C, 2008, 112, 9650-9658.

20 P. Hu, X. Wu, S. Hu, Z. Chen, H. Yan, Z. Xi, Y. Yu, G. Dai and Y. Liu, Photochem. Photobiol. Sci., 2016, 15, 260-265.

21 K. Xu, Z. Chen, L. Zhou, O. Zheng, X. Wu, L. Guo, B. Qiu, Z. Lin and G. Chen, Anal. Chem., 2015, 87, 816-820.

22 K. Selvaprakash and Y.-C. Chen, Biosens. Bioelectron., 2014, 61, 88-94. 